\title{
El capitalismo extractivo: el caso de Guyana
}

\author{
Dennis C. Canterbury \\ (traducción del inglés: Luis Rodolfo Morán Quiroz)
}

Resumen. El propósito de este artículo es analizar la actual situación de las industrias extractivas de Guyana a la luz de la creciente demanda global de minerales. Se centra, principalmente, en la minería de bauxita y oro, que constituye el corazón de las industrias extractivas en el país. ¿Cuál es el actual papel del capital extractivo en Guyana en el actual barullo por los minerales de las economías emergentes y los países capitalistas ricos? La observación básica es la siguiente: el capital de las economías emergentes está dedicado activamente a la producción de bauxita, mientras que el capital de los países capitalistas ricos se dedica a la exploración de yacimientos de metales que están a punto de comenzar la producción. En ausencia de una mina de oro de gran escala de propiedad extranjera, las minas de oro más pequeñas que se caracterizan por el capital nacional dominan el sector, que en la actualidad es el principal encargado de atraer divisas extranjeras al país.

Palabras Claveः capital extractivo, minería, bauxita, oro, Guyana.

AвStract. The purpose of this article is to analyze the current situation of extractive industries in Guyana in light of the growing global demand for minerals. It focuses primarily on bauxite and gold mining, which are at the heart of the country's extractive industries. What is the role of extractive capital in Guyana in the current rush for minerals in emerging economies and rich capitalist countries? The basic observation is the following: capital from emerging economies is actively dedicated to the production of bauxite, while capital from rich capitalist counties is dedicated to the exploration of metallic minerals, some of which are just about to begin production. In the absence of a gold mine large-scale foreignowned gold mines characterized by smaller domestic capital dominate the sector, which currently has the primary responsibility to attract foreign currency to the country.

KEYWORDS: extractive capital, mining, bauxite, gold, Guyana.

Dennis C. Canterbury es profesor del Departamento de Sociología, Antropología y Trabajo Social de la Eastern Connecticut State University, Estados Unidos. 


\section{INTRODUCCIÓN}

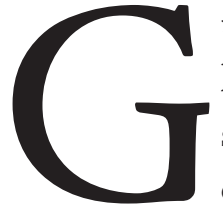

uyana es un pequeño país de habla inglesa ubicado en los salientes nororientales del subcontinente sudamericano con una superficie de 83 mil millas cuadradas y cuya población promedio era de 760,400, entre 2000 y $2011 .^{1}$ Las industrias extractivas en Guyana se caracterizan por la minería — diamantes, oro, cobre, bauxita, manganeso, lantánido-, productos forestales - madera para la construcción, contrachapado, leña, palma de manicol- y vida silvestre. La minería y los productos forestales, en particular la extracción de madera para construcción y la producción de contrachapa, son las principales áreas de concentración del capital extractivo. Los gobiernos de Guyana de los periodos poscolonial y postindependencia han generado dos posiciones opuestas para las industrias de extracción en el desarrollo económico del país. El Estado autoritario poscolonial entre los años setenta y principios de 1992 creían que si las alturas del mando de la economía eran propiedad de la nación, entonces las industrias extractivas que constituían su fundamento harían su máxima contribución al desarrollo económico del país. Para este fin, establecieron una política de nacionalizaciones de las compañías mineras de propiedad extranjera — de bauxita - en el país (Thomas, 1983).

El nuevo Estado autoritario (Canterbury, 2005), desde 1992 y hasta el presente, también ha puesto un gran énfasis en las industrias extractivas en el desarrollo económico del país (Ministry of Natural Resources and the Environment, 2012), pero privilegia el capital privado en vez del capital estatal. Se preocupa por abrir la economía a la inversión extranjera en las industrias extractivas, una característica del capitalismo neoliberal, en vez apostar por la propie-

/1/ Calculado a partir de los datos de una población estimada para 2000 a 2010 en el Reporte Anual del Banco de Guyana y en su Reporte y Declaración Anual de Cuentas (Report and Statement of Accounts) de 2011, Georgetown Guyana, 30 de marzo de 2012. 
dad nacional de los recursos naturales, marca del Estado autoritario poscolonial. Aunque la infraestructura legal es la adecuada para que el capital privado opere libremente, las élites estatales gobernantes ejercen un alto grado de micro administración y control respecto de quién puede invertir en la industria minera, para exasperación del capital extranjero (Department of State, 2012).

Sin embargo, aunque los Estados poscoloniales y los nuevos Estados autoritarios están a favor del capital estatal y privado, respectivamente, para que encabecen la contribución de las industrias de la extracción al desarrollo económico, el hecho es que ninguno de ellos ha logrado lo que se proponía. Los años de extracción de los recursos naturales de Guyana no han conseguido el desarrollo sustentable del país. La extracción de recursos naturales parece más una maldición que una bendición, aunque continúa siendo un pilar de la economía del país, como muestran los datos. El dilema consiste en que la propiedad del Estado ha producido una reacción inversa, en la que los países capitalistas ricos reducen su demanda de productos de las compañías nacionalizadas para castigarlos, mientras que la propiedad extranjera regresa a las condiciones de los arreglos del tipo mercantil en los cuales el capital extractivo opera con impunidad.

Ni la propiedad privada ni la estatal de la minería de bauxita en Guyana han significado una transformación económica positiva en las comunidades de la bauxita en Linden y Kwakwani. En el periodo inicial de la producción de bauxita el capital extractivo extranjero dejó muy poco en estas comunidades. Las luchas de la clase trabajadora en contra de las compañías mineras de bauxita eventualmente generaron mejoras significativas en las condiciones de trabajo y de vida, las que, por diversas razones, fueron anuladas nuevamente bajo la propiedad del Estado. Eso constituye una evidencia de que las cosas no están mejorando en el actual periodo. El sector de la minería de oro siempre ha estado en manos privadas, pero también ha sido incapaz de generar el requerido desarrollo económico sustentable de Guyana. Un enfoque alternativo sobre la extracción de recursos naturales que conlleva un desarrollo genuino a los países ricos en recursos sigue siendo muy necesaria. 


\section{INDICADORES ECONÓMICOS SELECCIONADOS E} IMPORTANCIA DE LAS INDUSTRIAS EXTRACTIVAS

\section{Exportaciones de mercancías}

principales 1990-2011

Las ganancias para la economía derivadas de las exportaciones se determinan por la cantidad de artículos exportados y sus precios unitarios en los mercados exteriores. Guyana es un adoptador de precios y por ende no tiene influencia en el precio de sus principales exportaciones. Las ganancias derivadas de las exportaciones de oro son un poco diferentes porque lo clasificado como producción de oro es, en realidad, de la declaración de oro.

Podemos, por ende, argumentar que la cantidad declarada de ganancias por el oro sería mayor si contáramos con la cifra real de oro producido en comparación con la que se mide en términos de la declaración de oro. Los recibos totales por exportación fluctuaron con una tendencia a la alta de 250.1 millones de dólares en 1990 a 1,128.8 millones de dólares en 2011.

Las industrias extractivas bauxita, oro y madera generaron el grueso de las ganancias por exportación al compararse con los recibos de las exportaciones agrícolas azúcar y arroz (tabla 1). La bauxita dominó las ganancias por exportación entre 1990 y 1992, pero a partir de 1993 el oro asumió la posición de principal ganador de divisas extranjeras. Las ganancias por la bauxita decayeron entre 1992 y 2006, nunca logrando su nivel de 1992 de \$97.1 millones de dólares. Las ganancias por bauxita comenzaron a mejorar desde \$65.5 millones de dólares en 2006 a 133.3 millones de dólares en 2007. Este incremento está asociado con la llegada de capital extractivo de origen ruso y chino en la industria de la bauxita de Guyana. Las ganancias derivadas de la exportación de madera alcanzaron un nivel máximo de $\$ 55.4$ millones de dólares en 2007 y acabaron en un nivel bajo de \$39.1 millones de dólares en 2011, debajo de las ganancias de 44.6 millones de dólares en 1997. El azúcar 
dominó las ganancias derivadas de las exportaciones agrícolas entre 1990 y 2009, pero en 2001 y 2011 el arroz produjo más ganancias que el azúcar.

TABLA I

Exportaciones de mercancías principales (millones de dólares)

1990-2011.

\begin{tabular}{|c|c|c|c|c|c|c|c|c|c|}
\hline AÑo & Total & BAUXITA & Oro & $\begin{array}{c}\text { BAUXITA } \\
\& \text { ORO }\end{array}$ & Madera & $\begin{array}{c}\text { Total } \\
\text { BAUXITA, } \\
\text { ORO Y } \\
\text { MADERA }\end{array}$ & AzúCAR & Arroz & $\begin{array}{c}\text { TOTAL } \\
\text { AZÚCAR } \\
\text { Y ARROZ }\end{array}$ \\
\hline 1990 & 250.1 & 80.4 & 17.7 & 98.8 & 4.5 & 103.3 & 79.9 & 13.7 & 93.6 \\
\hline 1991 & 254.4 & 82.3 & 21.4 & 103.7 & 4.0 & 107.7 & 89.8 & 18.0 & 104.8 \\
\hline 1992 & 363.4 & 97.1 & 24.6 & 121.7 & 3.7 & 125.4 & 134.1 & 35.0 & 169.1 \\
\hline 1993 & 404.0 & 91.1 & 99.8 & 190.9 & 4.5 & 195.4 & 116.3 & 33.0 & 149.3 \\
\hline 1994 & 447.4 & 76.4 & 128.0 & 204.4 & 7.9 & 212.3 & 116.4 & 55.6 & 172.0 \\
\hline 1995 & 478.9 & 82.9 & 94.7 & 177.6 & 8.3 & 185.9 & 125.5 & 76.5 & 202.0 \\
\hline 1996 & 552.8 & 69.8 & 103.5 & 173.3 & 8.9 & 182.2 & 150.7 & 93.8 & 244.5 \\
\hline 1997 & 573.4 & 89.4 & 139.8 & 229.2 & 44.6 & 273.8 & 133.4 & 84.7 & 218.1 \\
\hline 1998 & 525.0 & 78.5 & 124.0 & 202.5 & 31.0 & 233.0 & 129.0 & 73.3 & 202.3 \\
\hline 1999 & 504.8 & 77.2 & 108.7 & 185.9 & 37.3 & 223.2 & 136.2 & 71.1 & 207.3 \\
\hline 2000 & 502.7 & 76.3 & 123.3 & 199.6 & 35.2 & 234.8 & 118.8 & 51.8 & 170.6 \\
\hline 2001 & 490.3 & 61.0 & 127.0 & 188.0 & 33.0 & 221.0 & 109.2 & 50.2 & 159.4 \\
\hline 2002 & 495.5 & 35.3 & 136.2 & 171.5 & 35.5 & 207.0 & 119.5 & 45.5 & 165.0 \\
\hline 2003 & 512.8 & 40.4 & 130.9 & 171.3 & 30.7 & 202.0 & 129.2 & 45.3 & 174.5 \\
\hline 2004 & 589.0 & 44.7 & 145.1 & 189.8 & 45.0 & 234.8 & 136.5 & 55.1 & 191.6 \\
\hline 2005 & 550.9 & 62.8 & 111.9 & 174.7 & 49.6 & 224.3 & 118.0 & 22.4 & 140.4 \\
\hline 2006 & 585.1 & 65.5 & 114.4 & 179.9 & 55.0 & 234.9 & 137.0 & 54.6 & 191.6 \\
\hline 2007 & 698.0 & 101.5 & 153.1 & 254.6 & 55.4 & 310.0 & 150.1 & 75.3 & 225.4 \\
\hline 2008 & 801.5 & 131.1 & 203.7 & 334.8 & 53.8 & 388.6 & 133.4 & 118.0 & 251.4 \\
\hline 2009 & 768.2 & 79.5 & 281.7 & 361.2 & 41.4 & 402.6 & 119.8 & 114.1 & 233.9 \\
\hline 2010 & 885.0 & 114.2 & 346.4 & 460.6 & 48.5 & 509.1 & 101.5 & 151.3 & 252.8 \\
\hline 2011 & $1,128.8$ & 133.3 & 517.1 & 650.4 & 39.1 & 689.5 & 123.4 & 173.2 & 296.6 \\
\hline
\end{tabular}

Fuente: Bank of Guyana Annual Report and Statement of Accounts, varios números, 2001 y 2011. 
TABLA 2

Exportaciones de principales mercancías 1990-2012.

Contribución en porcentajes.

\begin{tabular}{|c|c|c|c|c|c|}
\hline AÑo & BAUXITA & Oro & $\begin{array}{c}\text { BAUXITA } \\
\text { Y ORO }\end{array}$ & $\begin{array}{c}\text { BAUXITA, } \\
\text { ORO Y } \\
\text { MADERA }\end{array}$ & $\begin{array}{c}\text { AzÚCAR Y } \\
\text { ARROZ }\end{array}$ \\
\hline 1990 & 32.1 & 7.0 & 39.5 & 41.3 & 37.4 \\
\hline 1991 & 32.3 & 8.4 & 40.7 & 42.3 & 41.1 \\
\hline 1992 & 26.7 & 6.7 & 33.4 & 34.5 & 46.5 \\
\hline 1993 & 22.5 & 24.7 & 47.2 & 48.3 & 36.9 \\
\hline 1994 & 17.0 & 28.6 & 45.6 & 47.4 & 38.4 \\
\hline 1995 & 17.3 & 19.7 & 37.0 & 38.8 & 42.1 \\
\hline 1996 & 12.6 & 18.7 & 31.3 & 32.9 & 44.2 \\
\hline 1997 & 15.5 & 24.3 & 39.9 & 47.7 & 38.0 \\
\hline 1998 & 14.9 & 23.6 & 38.5 & 44.3 & 38.5 \\
\hline 1999 & 15.2 & 21.5 & 36.8 & 44.2 & 41.0 \\
\hline 2000 & 15.1 & 24.5 & 39.7 & 46.7 & 33.9 \\
\hline 2001 & 12.4 & 25.9 & 38.3 & 45.0 & 32.5 \\
\hline 2002 & 7.1 & 27.4 & 34.6 & 41.7 & 33.2 \\
\hline 2003 & 7.8 & 25.5 & 33.4 & 39.9 & 34.0 \\
\hline 2004 & 7.5 & 24.6 & 32.2 & 39.8 & 32.5 \\
\hline 2005 & 11.3 & 20.3 & 31.7 & 40.7 & 25.4 \\
\hline 2006 & 11.1 & 19.5 & 30.7 & 40.1 & 32.7 \\
\hline 2007 & 14.5 & 21.9 & 36.4 & 44.4 & 32.2 \\
\hline 2008 & 16.3 & 25.4 & 41.7 & 48.4 & 31.3 \\
\hline 2009 & 10.3 & 36.6 & 47.0 & 52.4 & 30.4 \\
\hline 2010 & 12.9 & 39.1 & 52.0 & 57.5 & 28.5 \\
\hline 2011 & 11.8 & 45.8 & 57.6 & 61.0 & 26.2 \\
\hline
\end{tabular}

Fuente: Bank of Guyana Annual Report and Statement of Accounts, varios números, 2001 y 2011.

Las industrias extractivas - bauxita, oro y madera- contribuyeron con más del 50\% de las ganancias totales por exportación entre 2009 y 2010, y más de 60\% en 2011, mientras que la contribución de la agricultura decayó 
de $46.2 \%$ en 1992 a $26.2 \%$ en 2011 (tabla 2). La contribución porcentual de la agricultura a las ganancias totales por exportación fue mayor que el de las industrias extractivas sólo en 1992 (46.5\% comparado con 34.5\%), en 1995 (42.1\% comparado con $38.8 \%$ ) y 1996 (44.2\% comparado con $32.9 \%)$.

\section{Exportaciones según}

país de destino 2012

Azúcar, arroz, bauxita, oro y madera son los principales bienes de exportación de Guyana. Otras exportaciones incluyen pescado y camarón, frutas y verduras, productos farmacéuticos, ropa y accesorios, productos maderables, alimentos preparados, ron y otras bebidas espirituosas, diamantes, melazas, re-exportaciones y animales silvestres, efectos personales, artesanías y muebles de fibras naturales. Los principales lugares de destino de las exportaciones de Guyana fueron Estados Unidos, Canadá, Reino Unido, Jamaica, Trinidad y Tobago, Barbados, Bélgica, Portugal, Reino de Holanda y Suriname en 2001-2002 (Gobierno de Guyana, 2001 y 2002; Ministry of Foreign Trade and International Cooperation, 2003).

Estados Unidos, Reino Unido, Venezuela, Canadá, Trinidad y Tobago, Jamaica, Alemania, Ucrania, Holanda y Portugal fueron los principales países de destino de las exportaciones de Guyana en el periodo enero-septiembre de 2012. Estados Unidos compró la mayor cantidad de las exportaciones de Guyana, cerca de $37.0 \%$ en el periodo, y la contribución porcentual de las ganancias de las ventas a Estados Unidos respecto a las ventas totales fue de $22.5 \%$ (tabla 3 ).

El oro contribuyó con $51.1 \%$ de las ganancias por las exportaciones, seguido del arroz con $13.5 \%$; bauxita, $11.5 \%$, y azúcar, $8.1 \%$, entre enero y septiembre de 2012 (tabla 4). Las industrias extractivas - en particular oro, bauxita, madera y diamantes - representaron $66.2 \%$ de las ganancias totales por exportación en el periodo. 
TABLA 3

Exportaciones por país de destino, enero-septiembre 2012.

\begin{tabular}{lrr}
\hline \multicolumn{1}{c}{ País } & VAlor (Millones de dólares) & Contribución (\%) \\
\hline Estados Unidos & $215,837.9$ & 22.5 \\
Reino Unido & $100,762.6$ & 10.5 \\
Venezuela & $95,515.0$ & 10.0 \\
Canadá & $66,508.6$ & 6.9 \\
Trinidad y Tobago & $43,831.6$ & 4.6 \\
Jamaica & $36,231.7$ & 3.8 \\
Alemania & $35,788.6$ & 3.7 \\
Ucrania & $21,478.6$ & 2.2 \\
Reino de Holanda & $20,258.3$ & 2.1 \\
Portugal & $18,796.2$ & 2.0 \\
Otros países & $302,518.5$ & 31.6 \\
Total & $582,105.1$ & $100.0(99.9)$ \\
\hline
\end{tabular}

Fuente: Government of Guyana, Bureau of Statistics, enero 31, 2013.

Aunque la agricultura, productos maderables y pesca contribuyeron más que ninguno al рів, los datos acerca del valor en dólares estadounidenses de las principales exportaciones de Guyana (presentados en la tabla 3) mostraron que las industrias extractivas - bauxita, oro y madera- generaron la mayor cantidad de dinero para el país entre 1990 y 2011. Tal fue la situación a pesar de las fluctuaciones en las ganancias por exportaciones en las industrias de bauxita, oro y madera. Las ganancias por las exportaciones de estos artículos mostraron una tendencia creciente en el periodo considerado. Las ganancias por bauxita se incrementaron de 80.4 millones de dólares en 1990 a 133.3 millones de dólares en 2011. Sin duda, éste fue un mínimo incremento de 52.9 millones de dólares en un periodo de 22 años, un reflejo de los efectos del ajuste estructural en la industria de la bauxita. La situación fue diferente en las ganancias derivadas de las exportaciones de oro, que se incrementaron en 499.4 millones de dólares en el mismo periodo. Las ganancias combinadas 
de la exportación de bauxita y oro, empero, se incrementaron en 551.6 millones de dólares, principalmente impulsadas por la expansión en la declaración en oro y un mayor precio de mercancía por este metal precioso. Las ganancias por las exportaciones están relacionadas directamente con las fluctuaciones en los precios de las mercancías. El incremento en las ganancias derivadas de las exportaciones de madera fue de 34.6 millones de dólares.

TABLA 4

Exportaciones por artículo (incluye re-exportaciones), enero-septiembre 2012

\begin{tabular}{lrr}
\hline \multicolumn{1}{c}{ Artículo } & Valor (millones de dólares) & Contribución $(\%)$ \\
\hline Oro & $489,442.7$ & 51.1 \\
Arroz & $128,800.1$ & 13.5 \\
Bauxita & $110,063.9$ & 11.5 \\
Azúcar & $77,234.6$ & 8.1 \\
Camarón y gambas & $38,337.1$ & 4.0 \\
Madera & $29,149.3$ & 3.0 \\
Alimentos preparados & $17,747.3$ & 1.9 \\
Peces y derivados & $10,881.1$ & 1.1 \\
Diamante & $5,661.8$ & 0.6 \\
Melazas & $4,175.8$ & 0.4 \\
Otras Exportaciones & $28,702.0$ & 3.0 \\
Re-exportaciones & $17,331.8$ & 1.8 \\
Total & $582,105.1$ & 100.0 \\
\hline
\end{tabular}

Fuente: Government of Guyana, Bureau of Statistics, enero 31, 2013.

Las ganancias por el azúcar se elevaron de 79.9 millones de dólares en 1990 a 123.4 millones de dólares en 2011, únicamente 43.5 millones de dólares en 22 años. Este mínimo incremento es también un reflejo de los factores asociados con el ajuste estructural, las condiciones climáticas adversas, el clima de las relaciones industriales, la agenda de reciprocidad de la Organización 
Mundial de Comercio (oмc) y las fluctuaciones en los precios de las mercancías. Las ganancias derivadas de las exportaciones de arroz se incrementaron, no obstante, en 159.5 millones de dólares, mejorando por el ingreso de Guyana en la economía de mercado único del Caribe (Caribbean Single Market Economy - CSME-) en 2006. Venezuela es el mayor comprador del arroz de Guyana, alcanzando 55.72\% de las exportaciones de arroz, seguido del mercado Caricom que alcanza 26.08\% y la Unión Europea con 18.19\%. Jamaica, Trinidad y Tobago y Barbados son los mayores compradores de Caricom mientras que Portugal, Bélgica y Holanda encabezan la lista en la Unión Europea (Guyana Rice Development Board Annual Report, 2011, 2012).

\section{Producción mineral}

DECLARADA I980-20II

La información sobre la producción mineral declarada de Guyana entre 1980 y 2011 es bastante ilustrativa en varios aspectos (tabla 5). Primero, cubre el periodo del Estado autoritario poscolonial de 1980 a 1992 y del nuevo Estado autoritario de 1992 a 2011. Cubre también todo el periodo de ajuste estructural desde su puesta en práctica en 1988 hasta 2011. Una condicionalidad política de ajuste estructural fue la realización de elecciones «libres y justas». De tal forma, a partir de 1988 se preparó el terreno para las elecciones nacionales que tuvieron lugar en 1992 y llevaron al cambio político desde el Estado autoritario poscolonial al surgimiento de un nuevo Estado autoritario fundado en la democratización neoliberal.

El programa de ajuste estructural en 1988 derivó en la apertura de la economía al capital extranjero. La firma de propiedad canadiense Omai Gold Mines Limited comenzó su producción en 1993, el año posterior al cambio de gobierno en 1992. Fue el Estado autoritario poscolonial el que nacionalizó la compañía de propiedad canadiense Demerara Bauxite Company Limited, subsidiaria de Aluminum Company of Canada (ALCAN). 
TABLA 5

Producción mineral declarada, Guyana 1980-2011.

\begin{tabular}{|c|c|c|c|c|c|c|c|c|c|}
\hline AÑo & $\begin{array}{l}\text { Oro } \\
\text { No-OMAI } \\
\text { (Ozs) }\end{array}$ & $\begin{array}{l}\text { Oro } \\
\text { OMAI } \\
(\mathrm{Ozs})\end{array}$ & $\begin{array}{l}\text { Total } \\
\text { Oro } \\
\text { (Ozs) }\end{array}$ & $\begin{array}{l}\text { DiAmantes } \\
\text { (ANTIGUOS } \\
\text { KILATES } \\
\text { INGLESES) }\end{array}$ & $\begin{array}{l}\text { Piedra } \\
\text { (TONELADAS) }\end{array}$ & $\begin{array}{l}\text { ARENA } \\
\text { (TONELADAS) }\end{array}$ & $\begin{array}{l}\text { ArCilla } \\
\text { (TONELADAS) }\end{array}$ & $\begin{array}{l}\text { LATERITA } \\
\text { (TONELADAS) }\end{array}$ & $\begin{array}{l}\text { BAUXITA } \\
\text { (x IOOO } \\
\text { TONELADAS) }\end{array}$ \\
\hline 1980 & 11,003 & - & $11,003.00$ & $9,968.07$ & 89,912 & 12 & NA & NA & 1,626 \\
\hline 1981 & 19,263 & - & $19,263.00$ & 9.289 .98 & 71,823 & 396 & NA & NA & 1,503 \\
\hline 1982 & 8,655 & - & $8,655.00$ & $11,191.84$ & 28,112 & 1,054 & NA & NA & 1,174 \\
\hline 1983 & 5,039 & - & $5,039.00$ & $12,043.45$ & 41,622 & 477 & $\mathrm{NA}$ & NA & 1,091 \\
\hline 1984 & 11,132 & - & $11,132.00$ & $7,236.23$ & 38,975 & 217 & NA & NA & 1,333 \\
\hline 1985 & 10,328 & - & $10,328.00$ & $11,569.91$ & 22,112 & 2,019 & NA & NA & 1,573 \\
\hline 1986 & 14,036 & - & $14,036.00$ & $9,237.54$ & 33,847 & 2,366 & NA & NA & 1,470 \\
\hline 1987 & 21,415 & - & $21,415.00$ & $7,460.21$ & 24,335 & 2,717 & $\mathrm{NA}$ & NA & 1,359 \\
\hline 1988 & 18,803 & - & $18,803.00$ & $4,240,43$ & 11,755 & 9,505 & $\mathrm{NA}$ & NA & 1,339 \\
\hline 1989 & 17,343 & - & $17,343.00$ & $7,846.01$ & 61,492 & 11,173 & NA & NA & 1,333 \\
\hline 1990 & 38,717 & - & $38,717.00$ & $14,887.31$ & 3,288 & 43,995 & $\mathrm{NA}$ & NA & 1,456 \\
\hline 1991 & 59,296 & - & $59,296.00$ & $22,529.09$ & 63,377 & 17,017 & NA & NA & 2,204 \\
\hline 1992 & 79,581 & - & $79,581.00$ & $43,649.83$ & 13,260 & 90,021 & NA & NA & 2,336 \\
\hline 1993 & 87,100 & $202,299.96$ & $289,329.96$ & $48,773.52$ & 69,333 & 166,247 & NA & NA & 2,110 \\
\hline 1994 & 99,095 & $251,848.64$ & $530,943.64$ & $36,443.30$ & 92,525 & 751,357 & NA & NA & 2,091 \\
\hline 1995 & 91,451 & $178,356.15$ & $269,806.15$ & $51,049.35$ & 98,104 & 171,881 & NA & NA & 2,036 \\
\hline 1996 & 110,135 & $253,442.49$ & $363,557.49$ & $44,304.51$ & 336,506 & 118,917 & $\mathrm{NA}$ & $\mathrm{NA}$ & 2,369 \\
\hline 1997 & 98,051 & $333,567.81$ & $431,618.81$ & $34,675.63$ & 176,913 & 149,070 & NA & NA & 2,491 \\
\hline 1998 & 110,047 & $324,245.31$ & $434,292.31$ & $32,614.12$ & 32,445 & 290,619 & NA & $\mathrm{NA}$ & 2,489 \\
\hline 1999 & 110,684 & $312,089.79$ & $422,773.79$ & $44,246.19$ & 128,477 & 211,300 & 19,173 & $\mathrm{NA}$ & 2,539 \\
\hline 2000 & 105,289 & $329,603.37$ & $434,892.37$ & $79,557.94$ & 120,179 & 261,764 & 14,568 & 1,000 & 2,667 \\
\hline 2001 & 101,849 & $354,068.59$ & $455,917.59$ & $174,745.00$ & 117,904 & 243,127 & 43,275 & 12,000 & 1,953 \\
\hline 2002 & 117,240 & $319,431.00$ & $436,671.00$ & $241,905,22$ & 54,746 & 186,327 & 10,730 & 4,500 & 1,686 \\
\hline 2003 & 105,747 & $270,693.00$ & $376,440.00$ & $401,691.33$ & 154,093 & 253,674 & 10,677 & 5,250 & 1,882 \\
\hline 2004 & 116,236 & $242,192.00$ & $358,428.00$ & $433,242.45$ & 285,583 & 142,094 & 17,300 & 3,000 & 1,506 \\
\hline 2005 & 162,527 & $100,001.00$ & $262,528.00$ & $11,147.42$ & 315,964 & 573,150 & 4,000 & 12,00 & 1,648 \\
\hline 2006 & 205,970 & - & 205,970 & $330,637.00$ & 204,000 & 285,000 & 21,017 & 0 & 1,574 \\
\hline 2007 & 246,200 & - & 246,200 & $261,101.52$ & 368,008 & 715,500 & 15 & 0 & 2,239 \\
\hline 2008 & 260,387 & - & 260,387 & $164,010.69$ & 449,565 & 683,815 & 9,620 & 0 & 2,109 \\
\hline 2009 & 305,178 & - & 305,178 & $137,793.32$ & 340,016 & 478,572 & 2,000 & 0 & 1,448 \\
\hline 2010 & 308,438 & - & 308,438 & $48,467.74$ & 514,932 & 638,841 & 0 & 0 & 1,010 \\
\hline $2011^{\circ}$ & 363,083 & - & 363,083 & $52,273^{\star *}$ & $\mathrm{NA}$ & $\mathrm{NA}$ & NA & NA & 1,818 \\
\hline
\end{tabular}

Fuente: Guyana Geology and Mines Commission, Mineral Producción, Georgetown, Guyana. "La fuente de la información para 2011 es el reporte anual y la declaración de cuentas del Banco de Guyana, 2011. ${ }^{* *}$ Quilates de Malta. 
La producción declarada de oro antes de que operara Omai, una indicación de las actividades de los mineros en pequeña y mediana escala, en ningún momento estuvo entre 1980 y 1992 por encima de los niveles logrados entre 1993 y 2011. Es difícil, no obstante, determinar la exactitud de la producción de oro declarada durante el Estado autoritario poscolonial debido a la alta incidencia de contrabando de oro. Los mineros se inclinaban menos a vender su oro al Guyana Gold Board bajo el control del Estado autoritario poscolonial, así que pasaban de contrabando el oro hacia Venezuela, Suriname y Brasil.

El nuevo optimismo asociado con el cambio de gobierno en 1992 tuvo un efecto positivo en la producción declarada de oro. El optimismo se observó aun antes entre las firmas del capital extractivo cuando quedó claro que el gobierno de Guyana estaba por firmar un programa de ajuste estructural con el Fondo Monetario Internacional (FMI) y el Banco Mundial. Varias compañías extranjeras comenzaron la exploración de oro en Guyana a fines de la década de 1980. En 1985, dos firmas canadienses, Golden Star Resources Limited y Cambior, aseguraron derechos para iniciar la minería de oro en Guyana en una sociedad de joint venture con el gobierno de Guyana (Mars, 1998).

Efectivamente, «al menos diez compañías extranjeras comenzaron operaciones o exploraciones preliminares dentro de Guyana a fines de los años ochenta 1980» (Merrill, 1992). De estas compañías, «tres de las más grandes» eran «Golden Star Resources, Placer Dome de Canadá y Paranapanema de Brasil» (ibidem). Otras tres compañías mineras de importancia en operación eran «Giant Resources de Australia, Homestake Mining de Estados Unidos y Robertson Group de Gran Bretaña» (ibidem). Los mineros de oro a escala pequeña y mediana no se quedarían atrás con este incremento en la exploración en oro de parte de las compañías extranjeras.

Omai Gold Mines Limited emergió como «el primer productor de oro a gran escala en tener éxito» en Guyana, «al emplear avanzados métodos técnicos diseñados para maximizar la recuperación de oro a partir del yacimiento» (Thomas, 1998). Los tres principales accionistas en Omai eran Cambior Inc., Golden Star Resources y el gobierno de Guyana, cuya participación era de tan 
sólo 5\% (ibidem). Omai se convirtió en el mayor productor de oro en Guyana, lo que catapultó al sector de la minería de oro por encima de la agricultura y bauxita/alúmina como el principal generador de ganancias de divisas extranjeras para el país. Simultáneamente, la producción declarada de oro por los mineros a escala pequeña y mediana se incrementó constantemente en los años en que Omai estuvo operando.

Omai comenzó produciendo más de doscientos mil onzas de oro en los primeros dos años de sus operaciones y luego la producción declarada decayó en el tercer año. Este descenso estuvo asociado con el desastre ambiental que resultó del derrame de cianuro en el río Essequibo y que eliminó la vida marina, alteró el flujo de agua de muchas comunidades de la ribera y afectó negativamente las formas de sustento de los pueblos indígenas que dependían del río Essequibo de la pesca del río para alimentarse. La producción declarada de oro de Omai llegó a un punto alto de más de trescientos mil onzas en 2001, pero luego la compañía comenzó a diluir sus operaciones. Su producción declarada de oro decayó en cada año consecutivo posterior a 2001 y la compañía cerró sus operaciones en 2005, con 100,001 onzas.

Pero la producción declarada de oro por los mineros a pequeña y mediana escala continuó su tendencia ascendente. Efectivamente, en 2005 sobrepasó la producción declarada por Omai en más de 62 mil onzas. En 2011, la producción declarada de oro de parte de los mineros a pequeña y mediana escala sobrepasó la más alta declaración de Omai de 354,068.59 onzas en 2001. Los mineros de oro a pequeña y mediana escala en Guyana declararon una producción de 363,083 onzas en 2011.

Los mineros de oro en pequeña y mediana escala no se quedaron atrás respecto al actual precio elevado del oro en el mercado mundial y el aumento en la actividad de exploración que tuvo lugar en la industria del oro de Guyana de parte del capital extractivo de origen estadounidense, canadiense y australiano. El desastre financiero y la crisis económica que golpeó a los países capitalistas desarrollados han llevado a mucha gente a conservar sus recursos en oro, elevando el precio de esa mercancía. De tal modo, mientras 
que la producción declarada de oro por los mineros en pequeña y mediana escala fluctuaba, aunque con tendencias a la alza entre 1980 y 2006, sólo ha estado subiendo entre 2007 y 2011 los años de las crisis. Las firmas transnacionales que actualmente exploran en busca de oro en Guyana incluyen a Azimuth Resources Ltd., una compañía australiana; la compañía estadounidense Sandspring Resources Ltd. (oro-cobre), y las canadienses Guyana Goldfields Inc., Sacre-Coeur Minerals Ltd., gmv Minerals Inc., Guyana Frontier Mining Corp. y Takara Resources Inc. La Guyana Goldfields Inc. pronto habrá de comenzar la producción y se convertirá en el productor número uno de oro en Guyana, superando la producción combinada declarada de oro por los mineros en pequeña y mediana escala.

El contrabando de oro, la minería ilegal y la corrupción explican el marcado subregistro en la producción declarada de oro en Guyana. Se reporta que cerca de la mitad del oro producido se lleva de contrabando fuera del país por los mineros para obtener un mayor rendimiento del producto. El oro es contrabandeado hacia Brasil, Venezuela, Guyana francesa y, especialmente, Suriname. Según cálculos del gobierno, cerca de la mitad de las más de 600 mil onzas de oro producidas por los mineros en pequeña y mediana escala es objeto de contrabando hacia Surinam, al otro lado del río Courantyne (Edmonds, 2013).

En noviembre de 2012, por ejemplo, 70 lingotes de oro con un peso de 470 libras y con un valor de 11.5 millones de dólares fueron robados del bote con licencia de Guyana «mv Summer Bliss», mientras estaba anclado en la isla caribeña de Curaçao. Las fuentes en Guyana afirman que el oro era contrabandeado por las élites gobernantes, pero el gobierno negaba que el oro fuera originario de Guyana. No queda claro de quién era el oro, pero la policía arrestó a siete sospechosos en Curazao y las autoridades de Estados Unidos han confiscado 11 lingotes de oro que fueron enviados por correo de Curazao a Puerto Rico. Los lingotes de oro se encontraban en varios paquetes de correo en un aeropuerto en la ciudad puertorriqueña de Aguadilla. El valor estimado de los lingotes de oro, cuyo peso es de cerca de 77 libras, oscila en 1.7 millones dólares (Caribbean360, 12 de enero, 2013). 
La producción de bauxita fluctuó entre 1'091,000 y 2'667,000 toneladas en el periodo entre 1980 y 2011 (tabla 5). Las transnacionales chinas y rusas Bosai Minerals Group Inc. y Bauxita Company of Guyana, Inc. (BCGI), una subsidiaria de la rusa Russian Aluminum Company (RASUL), respectivamente, actualmente son las principales productoras de bauxita en Guyana. Los chinos explotan una mina en las tierras de McKenzie (ahora Linden), que previamente fue propiedad de ALCAN, y los rusos están explotando la mina de bauxita en Kwakwani que antes fue propiedad de la compañía minera estadounidense Reynolds. Estas dos compañías (estadounidense y canadiense) fueron nacionalizadas en los años setenta y fueron vendidas subsecuentemente a los rusos y chinos en 2004 y 2006, respectivamente. Los canadienses, no obstante, aún tienen una fuerte presencia en la industria de la bauxita en Guyana. La transnacional canadiense First Bauxita controla grandes extensiones en la importante faja costera de bauxita en Guyana. Las propiedades de la compañía incluyen Bonasika en el Essequibo, que antes fue excavada por ALCAN en los años cuarenta y sesenta (First Bauxite Corporation, 17 de agosto, 2012).

La producción de bauxita alcanzó una cima bajo el Estado autoritario poscolonial en 1992, el mismo año en que cambió el gobierno. La producción tuvo una tendencia a la alza entre 1988 y 1992, los años de ajuste estructural bajo el Estado autoritario poscolonial. Tal fue el caso también después de que el nuevo régimen autoritario asumió el poder en 1992. La compañía nacionalizada de bauxita en Linden estaba programada para ser privatizada según el acuerdo de ajuste estructural a fines de 1999. Al no lograr encontrar un comprador para ese momento, el gobierno solicitó a Cambior, la compañía propietaria de Omai Gold Mines Limited, que participara en la industria de la bauxita del país. Cambior estuvo bajo contrato para la minería de bauxita en Linden entre 1999 y 2004. La producción de bauxita alcanzó su nivel más alto de 2,667 toneladas en 2000, el máximo para todo el periodo entre 1980 y 2011, pero decayó para 2004. A pesar de este descenso, Cambior y el gobierno de Guyana establecieron una sociedad para crear juntos en Linden, en diciembre 2004, la Omai Bauxita Mining Inc. —Cambior era propietaria 
del 70\% y el gobierno de Guyana del 30\%- (Gobierno de Guyana, 2006). Cambior compró sus acciones de $70 \%$ por 10 millones de dólares — cinco millones en efectivo y cinco millones en equipo para la minería transferido desde minas de oro Omai, que fueron cerradas en 2005-. La compra incluyó la planta de energía, una compañía por separado denominada Omai Services Incorporated, que aportaba electricidad a la compañía de bauxita y a la comunidad. Cambior proyectaba invertir 40 millones de dólares en las operaciones de Omai Bauxita Mining.

Pero dos años después de que Cambior adquirió las operaciones de bauxita en Linden, ésta interrumpió temporalmente la producción, afirmando que se habían derrumbado las ventas de bauxita. La compañía señaló que experimentaba dificultades debido a las operaciones de los productores chinos de bauxita, quienes utilizaban carbón, una fuente barata de energía en su proceso de producción, en comparación con el petróleo que utilizaba Omai Bauxite Mining Inc. Los productores chinos de bauxita también fueron acusados de recibir subsidios del Estado, lo que les permitía vender a precio más bajo. El gobierno de Guyana, se reportó, había amenazado con llevar el asunto ante la OMC para ser indemnizado. Cambior aseguró a la comunidad de Linden que el cierre temporal de sus operaciones de bauxita no afectaría la oferta de electricidad porque la planta de energía de Omai Services Incorporated, que controlaba la planta, era una entidad por separado de la compañía minera, la Omai Bauxite Mining Inc.

Sin embargo, en el mismo 2006, Cambior vendió a iAmgold Corporation, una compañía canadiense de explotación minera del oro, en más de 1.2 miles de millones de dólares. IAmgold luego vendió Omai Bauxite Mining Inc. y Omai Services Incorporated por 46 millones de dólares a Bosai Minerals Group, una empresa china de propiedad privada en el mismo 2006. El gobierno de Guyana y Bosai firmaron un acuerdo para permitir a ésta última la compra de $70 \%$ de las acciones de овмі en febrero 2007.

El primer punto a resaltar aquí es que Omai Gold Mines Limited estaba reduciendo sus operaciones, las que estaban programadas para su cierre en 2005. Así pues, Cambior vendió su propio equipo de minería a sí misma, lo que 
en esencia era comprar la compañía de bauxita por sólo cinco millones de dólares. Segundo, cuando Bauxite Mining Inc y Omai Services Incorporated fueron vendidos no había evidencias de que Cambior hubiera hecho mayores inversiones en ellos. Tercero, sin duda alguna Cambior estaba haciendo arreglos secretos para su compra por IAMGOLD Corporation, al mismo tiempo que afirmaba que su operación de bauxita en Linden tenía que cerrarse temporalmente debido al alto costo de producción y prometía falsamente a la gente que continuaría suministrándoles electricidad. Cuarto, el pueblo de Guyana fue engañado y despojado de 41 millones de dólares porque Cambior realmente compró la compañía de bauxita por cinco millones y luego, sin inversión alguna, fue vendida por IAMGold Corporation a Bosai Mineral Group por 46 millones de dólares.

Bosai Minerals Group Inc. se estableció en 2004 y comprende más de 12 plantas, compañías subsidiarias y entidades ramales ubicadas en China, Guyana y Ghana. La compañía se dedica a la minería de minerales industriales, manufactura de fusión, comercio internacional y bienes raíces, y tenía un capital total de cinco mil millones de dólares a fines de 2009. Sus principales productos son el metal de aluminio, la alúmina de grado metalúrgico, alúmina marrón fundida, bauxita calcinada, combustible de coca y carbón. Bosai Minerals Group Inc. se ubica entre las 500 compañías privadas de mayor nivel de China, los 500 manufactureros chinos de mayor nivel y las 50 empresas chinas de metal no ferroso y es la número uno en la producción de bauxita calcinada y alúmina marrón fundida.

No sólo fueron los canadienses y los chinos quienes estuvieron involucrados en la industria de la bauxita en Guyana. En 2004, RAsul y el gobierno de Guyana fundaron la Guyana Bauxita Company Inc. (BCGI), con sede en Georgetown. RASUl es propietaria de $90 \%$ de la compañía y el gobierno de Guyana de 10\% (Gobierno de Guyana, 2006). Rasul adquirió Aroiama Mining Company del gobierno de Guyana en 2006, que fue transferida a Bauxite Company of Guyana el mismo año. RASul también tiene minas de bauxita en Kurubuka y Korite, que tienen un depósito combinado de cerca de 80 millones de toneladas. 
Pero, a pesar del hecho de que las compañías extranjeras son propietarias de la industria de la bauxita en Guyana, la producción en 2010 (1,010 miles de toneladas) se situó por debajo de lo que estuvo en 1980 (1'626,000 miles de toneladas). El fluctuante pero estable incremento en la producción de piedra y arena constituye un reflejo del rápido aumento en la construcción. Hubo una rápida producción de laterita en la primera mitad de la década de 2000, pero la producción se detuvo en 2006. La producción de arcilla comenzó en 1999, pero ha visto mejores épocas, pues el nivel de producción logrado en 2001 nunca más se ha logrado.

El lavado de dinero en la industria del oro constituye un serio problema que está asociado con el contrabando y el narcotráfico, y que tiene un impacto negativo en la producción declarada de oro. Según las fuentes entrevistadas, los vendedores de drogas utilizan la industria del oro y la minería como un medio para convertir su dinero sucio en dinero limpio. Los vendedores de droga compran oro con efectivo directamente a algunos pequeños mineros como parte de las operaciones de contrabando de oro y lavado de dinero. Los vendedores de droga que usan el frente de mineros de oro venden luego el oro al Guyana Gold Board para legitimar su dinero.

Pero el gobierno de Guyana recientemente se deslindó del informe de 2013 sobre la estrategia internacional de Estados Unidos para el control de narcóticos (United States International Narcotics Control Strategy Report), donde se señala que varias leyes para atacar el lavado de dinero y el contrabando de drogas no se estaban aplicando en Guyana. El informe afirmaba:

El gobierno de Guyana ha aprobado la legislación para permitir una respuesta más efectiva a la amenaza del tráfico de drogas. El decreto en contra del lavado de dinero y para contrarrestar el financiamiento de terrorismo, de 2009, la iniciativa para la intercepción de las comunicaciones y la iniciativa de procedimiento criminal fueron diseñados para mejorar las capacidades de investigación de las autoridades encargadas de aplicar la ley y los 
fiscales para arrestar a los traficantes de droga. Hasta la fecha, empero, el gobierno no ha realizado procesos judiciales bajo estas leyes (us Bureau of International Narcotics and Law Enforcement Affairs, 2013).

El gobierno afirma que las leyes son utilizadas para recopilar datos de inteligencia sobre el lavado de dinero y el tráfico de drogas (Chabrol, 2013).

En una acción policiaca denominada «Operación El Dorado», las autoridades de Guyana detuvieron al menos a 94 extranjeros provenientes, principalmente, de Brasil, dedicados a la minería ilegal en el país, en abril de 2012 (The Gleaner, 25 de abril, 2012). La operación implicó la inspección de minas, incluidas «revisiones sobre el estatus de la propiedad sobre la que se trabajaba, la verificación de los privilegios mineros y certificados de registro de las personas empleadas, la inspección de la documentación requerida, incluyendo las licencias de dragado y libros contabilidad de la producción, cumplimiento con los requerimientos de sanidad, ambientales y de salud y seguridad ocupacionales». La operación encontró que 32 mineros locales incumplían las regulaciones mineras de Guyana.

Debido a la corrupción y al bajo salario de los funcionarios de gobierno, empero, las regulaciones en el sector minero son escasamente aplicadas y vigiladas. Por ejemplo, la policía local acepta sobornos de los mineros clandestinos en vez de arrestarlos. Es ésta una de las causas del subregistro de la producción de oro.

\section{Papel del capital proveniente de} LAS ECONOMÍAS EMERGENTES

Un rasgo medular de las industrias extractivas en Guyana es el papel cada vez más considerable del capital proveniente de las economías emergentes. El capital extractivo proveniente de fuentes no tradicionales como Malaysia, China, 
Rusia e India se abocan a la producción en el país. El capital brasileño podría concebirse en busca de acaparar tierra para cultivar arroz, mientras que el capital estadounidense está haciendo lo mismo para envasar minerales geológicos raros y el capital de India está embarcado en un proceso similar. Éste es un cambio en comparación con la situación durante el periodo colonial, cuando el capital europeo, estadounidense y canadiense dominaba las industrias extractivas.

La firma transnacional malaya Samling Strategic Corporation Sdn. Bhd. (Sendirian Berhad, el equivalente malayo a incorporado), que opera una subsidiaria de Yaw Holding Sdn. Bhd, es la principal productora en el sector de los productos maderables a través de Barama Company Ltd. Esta firma, Barama, es la principal compañía de recursos forestales y maderables en $\mathrm{Gu}$ yana y emplea cerca de mil trabajadores. La compañía se dedica a la venta de troncos de madera noble y de madera aserrada y a la manufactura de productos de contrachapado, cubiertas y pisos de madera.

El fenómeno de acaparamiento de tierras a nivel global, donde los gobiernos y las corporaciones adquieren terrenos en países extranjeros para producir alimentos y minerales para exportar a los países inversionistas, ha llegado a Guyana (Bulkan, 2011). El acaparamiento de tierras en Guyana lo es más para la extracción de recursos naturales que para la producción agrícola y de biocombustibles. Pero no es porque el gobierno de Guyana no quisiera vender el país a los acaparadores de tierras dedicados a la producción agrícola. El gobierno de Guyana buscó vender tierras a inversionistas libios y estadounidenses para cultivar en proyectos agrícolas de enorme calado ( Guyana seeking agro-investors in the US», Farmland.org, 28 de noviembre, 2008), en su interés por convertir al país en un productor clave en la industria alimentaria multimillonaria del Caribe ( Guyana yet to see huge regional investment in agri sector», Farmland.org, 22 de junio, 2009) —la región importa casi cuatro mil millones de dólares en alimentos anualmente-. El gobierno de Guyana trabajó también con varios inversionistas interesados en los proyectos agrícolas de gran envergadura, entre ellos el cultivo de soya, ganado vacuno y arroz en Pirara en la región nueve del país. 
Paulo Cesar Quartiero, un productor arrocero a gran escala de origen brasileño, expresó su interés por comprar tierras en Guyana para propósitos agrícolas (GRAIN, 2010). RiceTec Inc., compañía multinacional con sede en Texas especializada en semillas, se acercó al gobierno de Guyana «por aproximadamente 2,000 hectáreas de tierra en la misma región» de sabana Rupunu$\mathrm{ni}$, «un ecosistema diverso y frágil que es el hogar de varios pueblos indígenas» (ibidem). La compañía Café Coffee Day (CDD), fabricante de café en India, obtuvo unos 1.8 millones de acres de tierras boscosas en Guyana en 2011, y está dedicada a su explotación para producir mobiliario de alta calidad. El gobierno de Guyana realizó el contrato de tierras de CDD con Vaitarna Holdings Private Inc. (VHPI), una subsidiaria de CDD, a la que «se le concedió un permiso de exploración forestal del estado (State Forest Exploratory Permit - SFEP-) que antes se había concedido a Simon and Shock Intl. (sSI), una compañía estadounidense, y un acuerdo de venta de madera (TSA) que antes se había concedido a Caribbean Resources Limited (CRL) (Kaieteur News, 2012)».

Hay una aglomeración en busca de elementos geológicos raros en Guyana, la que se ha convertido en un centro de atracción para el capital extractivo. Rare Earth Elements International, Inc. (REEI), una compañía con sede en Estados Unidos de exploración mineral, adquirió una propiedad de elementos geológicos raros en Port Kaituma, Guyana en 2012 («REE International Acquires Rare Earth Property With Estimated Value of \$10 Million», Marketwire, Mining and Metals, 20 de marzo, 2012). La propiedad incluye 44 millas cuadradas con más de 200 concesiones. La comisión geológica y de minas de Guyana (Geological and Mines Commission) estimó que en 2009 el depósito inicial de Colimbita-Tantalita por la tierra excede los 10 millones de dólares a precios actuales de mercado.

Además, Guyana tiene un papel en la creciente búsqueda global de uranio. Dos compañías mineras canadienses exploran actualmente en busca del mineral. La compañía minera canadiense U308 Corporation, con sede en Toronto, explora la cuenca del Roraima, donde tiene derechos de exploración para uranio en aproximadamente 1.3 millones de hectáreas. Argus Metals Corp. de Van- 
couver, Columbia Británica, Canadá, adquirió recientemente la licencia para explorar en busca de uranio en Port Kaituma (Argus Receives Title and Uranium License for the Large-scale, Drill-ready Kaituma Uranium/Gold Project Marketwire-Mining and Metals, 31 de enero, 2012), el área donde se ubicaba el famoso templo de Jim Jones, «Peoples Temple». Reunion Manganese Inc., subsidiaria plena de Reunion Gold Corporation de Canadá, explora en busca de manganeso y pronto comenzará la producción en Matthews Ridge.

Finalmente, «la producción y exportación potenciales de petróleo/gas natural» se considera «un "nuevo polo de crecimiento para la economía" de Guyana». La exploración de petróleo/gas natural se espera que comience nuevamente en 2014 tras su congelamiento debido a una disputa de fronteras marítimas con Surinam, pero que la ley internacional del Tribunal de Mares en Alemania declaró a favor de Guyana en 2007. Tullow Oil, una compañía británica, que tiene una joint venture con REPSOL de España, ha comenzado a excavar en la cuenca de Guyana-Surinam. CGX de Canadá ha reiniciado la exploración y «ha anunciado, con base en los resultados de las operaciones de su licencia de prospección de petróleo en Corentyna (Petroleum Prospecting License-PPL), que la producción se dará en la corriente en 2014» (Thomas, 2012).

\section{INCENTIVOS Y REGÍMENES FISCALES PARA}

LA EXTRACCIÓN Y LA INVERSIÓN EN MINERALES

Incentivos de inversión y regímenes fiscales ${ }^{2}$

El actual gobierno de Guyana aplica una agresiva política para atraer la inversión extranjera al país al proveer incentivos directos, incentivos especiales e incentivos sectoriales a los inversionistas. Los incentivos directos generales in-

/2/ Toda la información de esta sección está tomada de la Oficina de Inversión de Guyana, Georgetown (http://www.goinvest.gov.gy/index-2.html). 
cluyen «tasa cero en tarifas de aduanas e impuestos al consumo en la mayoría de las plantas, maquinaria y equipo». Las materias primas y los materiales de empaque utilizados en la producción por los manufactureros y las pequeñas empresas también gozan de una tasa cero en las tarifas aduanales y en impuesto al consumo. Hay un «traspaso ilimitado de las pérdidas de años anteriores, la depreciación acelerada en planta y equipo, la repatriación plena e irrestricta de capital, ganancias y dividendos» y el gozo de los «beneficios de los tratados de dobles tributación con Estados Unidos, Canadá y los países del Caricom».

Los incentivos especiales van a las firmas que generan productos no tradicionales para exportación. Estos implican «permisos de exportación para las exportaciones no tradicionales a los mercados fuera del Caricom», y «la cantidad real que se deduce depende de la proporción de las ventas exportación frente a las ventas totales». Si el porcentaje de las ventas de exportación frente a las ventas totales se ubica entre 10 y $20 \%$, el porcentaje de la ganancia de la exportación que es deducible del impuesto sobre la renta es de $25 \%$. Cuando se ubica entre 20 y $30 \%$, el porcentaje de la ganancia de la exportación deducible del impuesto sobre la renta es de 35\%. El deducible sube hasta $45 \%$ cuando las ventas de exportación frente a las ventas totales se ubican entre 30 y $40 \%$, y a $55 \%$ cuando las ventas de exportación frente a las ventas totales se ubican entre 40 y $50 \%$. Cuando está por encima de 60\%, el porcentaje de ganancia por exportación deducible del impuesto sobre la renta es $75 \%$.

Los incentivos especiales al sector minero incluyen «vacaciones tributarias, exención de tarifas e impuesto al consumo en una variedad de equipo para minería, equipo utilizado para limpiar terrenos y ciertos motores fuera de borda». Existen «una tasa preferencial de impuesto al consumo de $10 \%$ en combustible para aviación», $y$ «para la minería a gran escala, exención de tarifas e impuesto al consumo en combustible, maquinaria y refacciones para el equipo y en vehículos importados exclusivamente para la empresa». Los incentivos especiales de los que gozan los productos maderables incluyen «exenciones de tarifa e impuestos en motores fuera de borda de hasta $75 \mathrm{hp}$ » y $5 \%$ en aquellos motores que estén por encima de $75 \mathrm{hp}$. Los inversionistas en el sector de los productos madera- 
bles también gozan de «exención de tarifas e impuesto al consumo en el equipo utilizado para derribo de árboles, desarrollo de tierras y en molinos de madera».

El actual régimen fiscal habitual para la extracción de minerales en $\mathrm{Gu}$ yana es como sigue. Para la minería en gran escala - oro y metales preciosos, diamantes y piedras preciosas - la regalía es de $5 \%$ de producción o de los ingresos brutos. El impuesto a la renta es de $35 \%$ y la tasa de depreciación es de $20 \%$. Las tarifas y el impuesto al consumo está fijado en cero en «todo el equipo, procesar materiales y refacciones que se usarán durante y al final de las exploraciones, prospección y minería». No existe una «equidad gratuita» para el Estado, pero el Estado tiene «el derecho de nominar un miembro del consejo» de estas compañías. El impuesto a retener es de 6.25\% de los dividendos. La «cláusula de estabilidad» estipula que «por cada mina desarrollada» todas las condiciones se mantienen por « 15 años a partir del inicio de la producción comercial o la vida del depósito, cualquiera sea menor, luego se aplican las reglas generales por tarifas, impuesto sobre la renta e impuesto retenido».

La bauxita y otros minerales, con excepción de la arena y la piedra, pagan una regalía de « $1.5 \%$ del producto o de los ingresos brutos o por los costos de producción al salir de la planta, el que sea mayor». Después, todas las otras condiciones del régimen fiscal que se aplican al oro se aplican a la bauxita. La regalía por la minería de oro en pequeña y mediana escala es de $5 \%$ del ingreso bruto para el oro y de $3 \%$ del ingreso bruto para los diamantes. Los mineros pequeños y medianos pagan $2 \%$ del ingreso bruto en vez de impuestos sobre la renta, $y$ «si el permisionario es una corporación, el impuesto corporativo es pagadero con una tasa de 35\% del ingreso gravable». Además, gozan de «exenciones de tarifas y de consumo en una variedad de artículos».

Inversión total 1999-2010

El valor de la inversión total en Guyana se incrementó en más de 100\% entre 1999 y 2010. El sector gubernamental encabezaba en el valor de la inversión 
total 2010 con 303 millones de dólares, en comparación con 281.5 millones de dólares en el sector privado. Sin embargo, la inversión total en el sector público durante el periodo considerado fue menor que en el sector privado -1,874 millones de dólares en comparación con 2,356 millones (tabla 8).

TABLA 6

Inversión total 1999-2010.

\begin{tabular}{ccrr}
\hline Años & $\begin{array}{c}\text { Privada } \\
\text { (local \& IED })\end{array}$ & $\begin{array}{c}\text { Pública } \\
\text { (gobierno) }\end{array}$ & Inversión total \\
\hline \multicolumn{4}{c}{ Valor en millones de dólares } \\
1999 & 157.0 & 81.0 & \\
2000 & 152.0 & 98.5 & 238.0 \\
2001 & 166.0 & 91.0 & 250.5 \\
2002 & 162.0 & 101.5 & 257.0 \\
2003 & 155.5 & 97.0 & 263.5 \\
2004 & 152.5 & 98.0 & 252.5 \\
2005 & 157.0 & 109.5 & 250.5 \\
2006 & 205.0 & 209.0 & 266.5 \\
2007 & 222.5 & 211.5 & 414.0 \\
2008 & 259.5 & 209.0 & 434.0 \\
2009 & 285.5 & 265.0 & 468.5 \\
2010 & 281.5 & 303.0 & 550.5 \\
\hline
\end{tabular}

Fuente: us State Department, 2012 Investment

Climate Statement-Guyana.

En los años de la gran recesión 2007-2008, la inversión privada extranjera y local, así como la inversión total se incrementaron, indicando que la crisis no afectó inmediatamente la inversión en esas áreas. Pero la inversión del sector público se redujo entre 2007 y 2008, aunque se incrementó tanto en 2009 como en 2010. Sin embargo, la inversión extranjera y local decayó entre 2009 y 2010. Probablemente, el descenso en la inversión privada y local 
es una señal de que la crisis opera con un rezago en las economías que no fueron afectadas inmediatamente por la caída financiera en los países capitalistas ricos en 2007-2008. Pero la IED total se incrementó consistentemente desde 2007, como si la gran recesión no tuviera efecto real (tabla 6).

Inversión extranjera directa 2007-2010

Los datos sobre IED por sector mostraron que el transporte y la telecomunicación fueron los mayores receptores en el periodo 2007 a 2010 (tabla 7).

TABLA 7

Inversión extranjera directa por sector 2007-2010

(valor en millones de dólares).

\begin{tabular}{lrrrr}
\hline Sector & 2007 & 2008 & 2009 & 2010 \\
\hline Agro, productos maderables, pesca & 22.6 & 41.2 & 15.0 & 17.2 \\
Energía & 7.0 & 1.3 & 8.2 & 13.0 \\
Minería y extracción & 42.1 & 22.0 & 42.1 & 64.0 \\
Manufactura & 5.0 & 14.9 & 7.8 & 15.5 \\
Turismo y hospitalidad & 5.4 & 23.7 & 12.5 & 16.0 \\
Transporte y telecomunicación & 51.2 & 53.3 & 64.0 & 54.0 \\
Otros & 19.2 & 5.1 & 14.4 & 18.3 \\
Total & 152.5 & 161.5 & 164.0 & 198.0 \\
\hline
\end{tabular}

Fuente: us State Department, 2012 Investment Climate Statement-Guyana.

La minería y la extracción fueron el segundo mayor receptor de IED en el periodo, seguidas por la agricultura, los productos maderables y la pesca. Sin embargo, en 2010 la minería y la extracción atrajeron la mayor cantidad de IED, 64 millones de dólares comparados con 54 millones del sector de transporte y telecomunicación. 


\section{LAS INDUSTRIAS EXTRACTIVAS Y el ambiente en Guyana}

Las industrias extractivas de Guyana han derivado en importantes problemas para el ambiente y los pueblos indígenas. Trevin y Nasi (2009), por ejemplo, proporcionan un muy detallado análisis descriptivo de la estructura de gobernanza en el sector de los productos maderables ('Trevin y Nasi, 2009). Concluyeron que, aunque existen mecanismos modernos de protección al ambiente en Guyana, «la puesta en operación en la práctica de estos instrumentos legales y políticas sufre de los problemas del subdesarrollo como una escasa infraestructura, pocos especialistas calificados y limitados recursos financieros». Han identificado varias dificultades relacionadas con la gobernanza de los bosques en Guyana, como los temas de las tierras indígenas, incluyendo los derechos de tenencia, demarcación de terrenos, cosechas ilegales y emisiones nocivas.

El más infame de los desastres ambientales en las industrias extractivas de Guyana fue cuando los relaves en las minas de oro de Omai se rompieron y dejaron escapar lodos de cianuro y otras sustancias nocivas en los ríos de Omai y Essequibo en agosto de 1995. Hubo un derrame previo en mayo de 1995 que mató muchos peces en el río Omai. El impacto de este derrame llevó al establecimiento de una comisión de investigación sobre el desastre.

El informe de la comisión sobre el impacto en el ambiente del derrame mencionaba que la contaminación del sedimento del río con metales pesados era un tema clave. Afirmaba que «las principales formas de complejos de cianuro metálico presentes en los [relaves] eran ferrocianuro y cuprocianuro», lo que «comprende al $80 \%$ del total del cianuro presente en el agua de los relaves» (Report of Commission of Inquiry Into Discharge of Cyanide and Other Noxious Substances Into the Omai and Essequibo Rivers, Georgetown, Guyana, 5 de enero, 1996). Informaba que por lo general hubo una «muy alta concentración de cianuro, hierro y cobre en el río Omai durante el derrame», y que «la vida acuática fue afectada a todo lo largo del río Omai en donde se 
recolectaron 346 peces muertos». El río Omai registró los más altos niveles de contaminación por cianuro y metales pesados.

Históricamente, la producción de bauxita ha estado asociada con problemas sociales, de salud y ambientales en el pueblo de bauxita de Linden. Se identifican problemas de salud y ambientales en cada uno de los niveles del proceso de producción, que va desde la remoción de la sobrecarga para extraer el polvo de bauxita, hasta la etapa en que se calcina ese polvo (Dev Rawana, 1998). La excavación de la sobrecarga y del polvo de bauxita deja grandes hoyos en la tierra, espacios donde se junta agua de lluvia, proliferan los mosquitos y los niños se ahogan. Varias sustancias nocivas se acumulan en el agua y son fuente de problemas de salud para los niños que nadan en los estanques. La contaminación del aire es otro problema ambiental debido a la descarga de polvo de bauxita y los productos de la combustión cuando se calcina el polvo. La contaminación del aire en Linden está asociada con problemas respiratorios y oculares que enfrentan los residentes y que generan sensaciones de nausea entre ellos. La contaminación del agua y el suelo debido a la descarga de desechos tóxicos afecta a la población de peces y destruye cultivos y vegetación (ibidem).

La degradación física en el ambiente y la contaminación causada por la minería son otros importantes problemas de preocupación. Los mineros en pequeña escala en Guyana son acusados por la destrucción de los bosques, las riveras de los ríos, la contaminación por mercurio y la generación de una pesada carga de sedimentos en los ríos (ibidem).

Se ha puesto una mayor atención en el ambiente en Guyana a la luz del énfasis en las industrias extractivas como un polo de crecimiento económico en el país. El gobierno ha ingresado en la estrategia de desarrollo de bajo carbono (Low Carbon Development Strategy, LCDS) con Noruega y así dominar el potencial de la selva tropical de Guyana y poner al país en una vía de desarrollo de bajo carbono dentro del marco de la iniciativa global para reducir las emisiones derivadas de la deforestación y la degradación (REDD). Este provee una compensación para Guyana si evita la deforestación de su selva tropical, combate el cambio climático, protege biodiversidad y promueve el desarrollo sustentable. 
La estrategia de desarrollo de bajo carbono (LCDS) tiene significativas debilidades (Thomas, 2012), entre ellas su fundamento, un «inocente análisis económico marginal neoclásico». Aunque LCDS es supuestamente una sociedad entre Guyana y Noruega, el gobierno noruego «evita comprometerse con adoptar una sola acción nacional respecto al cambio climático, el calentamiento global o la reducción de las emisiones de Co 2 en la atmósfera» en Noruega, mientras que «el principal tema de acuerdo en relación con estos asuntos es la disposición de los "bosques prístinos" de Guyana». Noruega, en un cálculo per capita, es uno de los principales contaminadores del ambiente globalmente debido a que su economía se fundamenta en recursos naturales - petróleo, gas, industrias intensivas en energía, productos maderables y pescaderías-. La naturaleza unilateral del acuerdo enfatiza una forma de imperialismo ambiental, a medida que los países ricos buscan esquilmar a los países pobres del uso de sus recursos naturales bajo el disfraz de protección ambiental. El primer ministro de Noruega declaró públicamente que «su meta al ofrecer financiar a los países con selvas tropicales está diseñada para animar su secuestro de carbón de modo que se "aseguren los fiordos de Noruega para las futuras generaciones"» (Thomas, 2012).

\section{Resistencia y CAPital extractivo}

Represión y quebranto sindical en

la industria de la bauxita

La actividad minera en Guyana ha producido varias situaciones conflictivas en épocas recientes en las industrias de la bauxita y oro con los pueblos indígenas, los mineros en pequeña escala y las mujeres. El conflicto en la industria de la bauxita en Linden — desatado por el modus operandi de Bosai Minerals Group, Inc. y la decisión del gobierno de Guyana para incrementar la tarifa de la electricidad en el área- ha sido el más serio y brutalmente reprimido en la memoria reciente. El conflicto ha evocado la forma más extrema de vio- 
lencia de Estado, cuando el 18 de julio de 2012 la policía abrió fuego contra una multitud de manifestantes pacíficos, matando a tres de ellos - Shemroy Bouyea de 24 años de edad, Allan Lewis de 46 años y Ron Somerset de 17 años- e hiriendo a muchos otros. Fue ésta la primera vez, desde que Guyana obtuvo su independencia política de Reino Unido, que ese país experimentó tales niveles de violencia de Estado en contra de los manifestantes. Los disparos en Linden recuerdan los levantamientos de Ruimveldt en 1905 y los de Enmore en 1948, cuando la policía colonial en esas ocasiones abrió fuego sobre trabajadores inocentes, matando o hiriendo a varios de ellos.

Bosai Minerals Group, Inc y el gobierno de Guyana están en el mismo lado, mientras que los trabajadores están en el otro bando. El gobierno anunció, por medio del ministro de finanzas, que en su presupuesto anual iba a incrementar las tarifas de electricidad en la comunidad minera de bauxita en Linden a partir del 1 de julio de 2012. El incremento propuesto en las tarifas de electricidad se justificaba sobre la base de que «la electricidad cuesta entre 5 y 15 por $\mathrm{kWh}$ » en Linden, «mientras que en la compañía de fuerza y luz (Guyana Power and Light, GPL) los consumidores en red pagan un promedio de 64 por $\mathrm{kWh}$ ». El gobierno afirmó que el «costo total de este subsidio de la electricidad» a Linden «era de 2.9 miles de millones» en 2011, lo que es «equivalente al 10\% de los ingresos totales de GPL» (Gobierno de Guyana, 2012: 38). El presidente de Guyana afirmó que la creciente población de Linden era una de las razones para el alto subsidio de la electricidad y que la oposición política, cuando estuvo en el gobierno, quería aumentar las tarifas de electricidad en Linden. El presidente hizo saber que el gobierno subsidiaba la electricidad en Linden para hacer la compañía de bauxita más atractiva para los inversionistas extranjeros, pero que el subsidio desanimaba la conservación de energía. Los trabajadores de Linden tomaron las calles en una manifestación pacífica en contra de las propuestas del gobierno de incrementar las tarifas de electricidad. El gobierno respondió con disparos de fuego.

Los disparos de la policía y el lanzamiento de gas lacrimógeno a los manifestantes pacíficos — mujeres, niños y hombres — desató la inquietud social. 
Varios edificios en Linden fueron incendiados por completo y las carreteras fueron bloqueadas con desechos, madera, llantas quemadas y trincheras. El fuego destruyó un edificio que albergaba a varias dependencias de gobierno, entre ellas Guyana Revenue Services, Linden Care Foundation y el Institute of Distance and Continuing Education. La escuela primaria One Mile - la de mayor tamaño de este tipo en la región 10, que atendía a 830 estudiantes_-, la Linden Electricity Company Inc, las oficinas del Ministerio de Agricultura, la Guyana Energy Agency y el Linmine Secretariat acabaron incendiadas. El fuego arrasó otros dos edificios, al igual que las casetas de cobro de peaje, de seguridad y de la Guyana Energy Agency en el puente Mackenzie-Wismar, y se realizó un intento por quemar el puente. El puente Mackenzie-Wismar es la puerta de entrada por carretera a las regiones más silvestres de Guyana, donde se ubican las minas de oro y las industrias de productos maderables. La ruta alternativa es a través de la carretera Bartica-Potaro, que es mucho más larga y costosa.

Hubo un apoyo considerable, nacional y desde el extranjero, para los manifestantes, incluso desde el partido de oposición A Party for National Unity (APNU), una coalición de partidos políticos que incluye a Peoplés $\mathrm{Na}$ tional Congress (PNC), Working People's Alliance (WPA), Guyana Action Party (GAP), National Front Alliance (NFA) y Alliance for Change (AFC).

El gobierno estableció una comisión de investigación para examinar las manifestaciones sociales y los disparos de la policía. La comisión realizó audiencias y sometió su informe al presidente de Guyana en febrero 2013. Encontró que la policía era la responsable de los disparos pero que, aunque la descarga «fue un tanto desordenada», estaba «justificada» porque la multitud era «hostil» y culpaba a los organizadores y a los políticos por la escalada del conflicto. La comisión recomendó ocho millones de dólares guyaneses como compensación para las familias de las personas que fueron muertas. Los familiares de Shemroy Bouyea y Allan Lewis recibieron, cada uno, tres millones, y los de Ron Somerset dos millones. Las familias afirman que el dinero entregado es insuficiente para compensar por las vidas de sus seres amados. La co- 
misión también recomendó la compensación a los heridos y a los propietarios de fincas (Chabrol, 2013).

La dimensión de clase en la lucha se hizo bastante evidente en la respuesta de los magnates en la industria de la minería de oro. El bloqueo del puente Mackenzie-Wismar tuvo un efecto negativo en las comunidades mineras de oro, que no podían conseguir alimentos, combustible y otros artículos de primera necesidad porque el tráfico de vehículos hacia esas regiones se interrumpió. Algunos magnates del oro adoptaron una postura en contra de los manifestantes, exigiendo a la policía que despejara el puente para permitir que pasara la carga hacia la región. El comisario regional para la Región 10 reportó que en una asamblea algunos de estos individuos amenazaron con disparar a los manifestantes. Estos individuos son considerados mineros en pequeña escala, muchos de los cuales salieron de las filas de la clase trabajadora, pero cuyos intereses de clase coincidían ahora con las élites que gobiernan en Guyana. La Cámara de Comercio y Desarrollo de Linden adoptó una postura distinta que estaba más relacionada con la asumida por los trabajadores. Sus miembros también iban a ser afectados negativamente por el incremento en las tarifas de electricidad, así que les favorecería cerrar sus negocios y unirse a los trabajadores de la bauxita si esa acción llevaría eventualmente a bajar las tarifas.

Bosai produce electricidad por medio de Bosai Minerals Services Inc, quien la vende a la comunidad de Linden. El gobierno de Guyana paga a Bosai por la electricidad que aporta a Linden. Sin duda, Bosai tuvo una participación en la inquietud social en Linden, como puede inferirse al examinar algunos de los hechos respecto a las operaciones de la compañía en Guyana. ${ }^{3}$ Primero, Bosai Minerals Services Inc. aporta electricidad tanto a las operaciones de bauxita de Bosai Minerals Group, Inc, en Linden como a la comunidad de Linden. Pero hay una disparidad entre lo que afirma Bosai Minerals Services Inc, respecto a sus ganancias en 2012 y lo que muestran los registros públicos.

\footnotetext{
${ }^{13 /}$ Estos datos fueron tomados de Ram (2012).
} 
Bosai afirma que logró una ganancia de 233 mil dólares en 2010, mientras que los registros públicos «muestran que la compañía logró una ganancia (antes de impuestos) de 76³42,000 millones de dólares guyaneses, el equivalente en dólares estadounidenses de 380 mil dólares».

Segundo, Bosai Minerals Services Inc. está obteniendo ganancias del subsidio gubernamental a la electricidad. Los contribuyentes guyaneses están subsidiando por tanto a una compañía transnacional china para que provea electricidad a Linden por una ganancia notable. De tal modo, el subsidio del gobierno no está determinado únicamente por el consumo de electricidad de los residentes de Linden. Otros dos factores influyen en la magnitud del subsidio del gobierno: la producción de bauxita de Bosai, que también utiliza la electricidad que provee Bosai Minerals Services Inc., y el margen de ganancia de Bosai Minerals Services Inc.

Tercero, los datos financieros sugieren que Bosai Minerals Group compra combustible de la compañía estatal de petróleo de Surinam (State Oil Company of Surinam) a un precio más bajo de lo que paga Bosai Minerals Services Inc, por el combustible con el mismo proveedor.

Cuarto, la Comisión de Servicios Públicos (Public Utilities Commission, PUC) regula los servicios de electricidad en Guyana pero Bosai no se rige por puc. De tal modo, Bosai opera fuera de las leyes de Guyana y puede cobrar a la comunidad de Linden lo que desee por la electricidad. El gobierno de Guyana presenta una imagen en el sentido de que el subsidio a la electricidad en Linden drena la economía del país, pero las ganancias nacionales de las operaciones de Bosai muestran que es de otro modo. Al gobierno se le pagaron 440 millones en utilidades por las operaciones de bauxita en 2010 y además recibió 708 millones de impuestos corporativos.

La firma de propiedad rusa BCGI y el gobierno de Guyana están en el mismo lado, mientras que el sindicato Guyana Bauxita and General Workers' Union (GB\&GWU) y el pueblo trabajador están juntos en la lucha en contra de las tácticas de quebranto sindical de BCGI. Es una lucha prolongada que ha continuado por los pasados tres años. Los trabajadores en BCGI recurrieron a la 
acción industrial cuando la compañía propuso despedir a 75 trabajadores en 2009 , a cambio de un aumento de sueldo de $10 \%$ para quienes continuaran empleados en la compañía (Reuters, 24 de noviembre, 2009). En la lucha que se sucedió, la compañía suspendió su contrato laboral con GB\&GWU. La firma BCGI luego desconoció al sindicato al amenazar a los trabajadores para que firmaran una petición que preparó para ese efecto como condición para ser empleado. La compañía generó cartas de suspensión a varios trabajadores implicados en la huelga, pero el sindicato у всGі llegaron al acuerdo de que las cartas de suspensión entregadas a los trabajadores serían retiradas. En cambio, la compañía generó cartas de despido a los trabajadores al mismo tiempo que negociaba los términos de la reanudación con el sindicato para concluir la huelga.

El sindicato dejó la mesa de negociaciones y la compañía anunció que habían cesado sus operaciones en Guyana indefinidamente. Los trabajadores protestaron bloqueando carreteras y alterando los horarios de vuelos en la pista de Kwakwani. El gobierno de Guyana intervino con lentitud para ayudar a resolver la disputa y pidió disculpas a nombre de BCGI, afirmando que mientras que en otros países las compañías de bauxita cerraban sus puertas y se iban, en Guyana RASUl y Bosai Minerals Group Inc. no lo han hecho sino que están tratando de minimizar el impacto de la reducción global en los empleos. Para sacar a GB\&GWU, la compañía recurrió a la formación de un Comité de Trabajadores tras su fallido intento por hacer que los trabajadores firmaran para convocar a la National Association of Agricultural, Commercial and Industrial Employees (NAACIE), donde el Ministro del Trabajo tiene influencias como agente negociador rumbo a la violación de la ley de reconocimiento y certificación de los sindicatos (Trade Union Recognition and Certification Act, chapter 98: 07).

Pueblos indigenas, pequeños mineros y mujeres

Sin duda, la extracción de recursos naturales está teniendo un impacto debilitante en los pueblos indígenas y ha generado situaciones de conflicto con 
los pequeños mineros, así como con las mujeres. Guyana es el hogar de siete grupos indígenas - akawaio, arekuna, caribe (río Barima), macusi, patamona, waiwai y wapisiana-. Mientras que los pueblos caribe, akawaio, arekune y patamona ocupan las riveras de los ríos hacia Venezuela en el oeste de Guyana, los macusi y los wapisiana viven en la región de sabanas del norte y sur de Rupununi y los waiwai viven en el sur del río Essequibo. Todos hablan idiomas derivados del caribe, con excepción de los wapisiana, quienes hablan un idioma arawak (Edwards y Gibson, 1979).

Los pueblos indígenas en Guyana han participado históricamente en técnicas mineras artesanales tradicionales: cubeta, tamiz y cacerola, sin productos químicos. En algunos casos operan dragadoras de propiedad de la comunidad y también trabajan en jornadas de dragado y de minería de pozos de propiedad de personas ajenas a los pueblos indígenas. Las minas de oro de escala grande y mediana con dragado y las minas a cielo abierto tienen importantes efectos sociales y ambientales en las comunidades locales. Las riveras son dañadas y debilitadas y los canales son ampliados, lo que deriva en que los árboles se precipiten en los ríos y en cambios que redundan en que los canales de los ríos dejen de ser navegables. El aumento en turbiedad de «ríos y arroyos deriva en visibilidad reducida y en penetración de la luz en el agua»y causa «una reducción de la capacidad de fotosíntesis de las plantas acuáticas, acabando con frecuencia en la muerte o la inhibición de la respiración de algunas especies de peces, lo que desemboca en su muerte» (Demerara Waves, 5 de julio, 2012). El gobierno indicó que «la muerte de unas cuantas especies susceptibles causa importantes impactos en la red alimenticia y puede derivar en una reducción de las especies de agua dulce, que son la fuente primordial de alimento para las comunidades de las riveras» (ibidem). La minería en el río contamina el agua potable y genera «enormes islas de arena y grava que restringen el flujo de agua y producen inundaciones río arriba y devalúan el ingreso derivado del turismo en Guyana, incluida la pesca deportiva» (ibidem). Las comunidades indígenas río abajo de las operaciones activas de dragado se quejan de que no pueden acudir a la pesca y la caza de subsistencia, al lavado o 
al baño y no tienen acceso al agua potable cerca de sus asentamientos. La vida silvestre también está desapareciendo debido al ruido del equipo, el agua sucia y el aumento de la actividad humana en la región.

Los jóvenes y las mujeres indígenas están expuestos a explotación sexual y a los empleos mal pagados en los campos mineros en donde utilizan compuestos químicos tóxicos y dragados. La prostitución, el tráfico de drogas y de personas son otros problemas significativos. Los problemas de salud que enfrentan las comunidades incluyen el envenenamiento por mercurio, la malaria, el tifo, el dengue, la diabetes (Griffiths y Anselmo, 2010). La higiene es un problema considerable debido a las inadecuadas instalaciones para el desalojo de los desechos humanos y de otro tipo. La higiene inadecuada es una de las causas de la alta incidencia de malaria y tifo. La inflación en los precios dentro de las comunidades de minería de oro se da a partir de las condiciones monopólicas y oligopólicas bajo las cuales operan las empresas en esas áreas (ibidem). Los mineros pueden también excavar en las principales carreteras o desenterrar las principales tuberías subterráneas de agua provistas por el Estado en su búsqueda de oro (Wilkinson, 2012), aumentando así los problemas de transporte y agua. Hay un incremento en los delitos — asesinatos, sospechas de asesinato, desapariciones, robos a mano armada, violación y abuso en los campos de oro-, en su gran mayoría sin resolver. Sin duda, los costos en salud, ambientales, sociales y culturales para las comunidades indígenas son mucho mayores que los beneficios en efectivo que les llegan derivados de la minería.

Griffiths y Anselmo (2010) señalaron que los desafíos que plantea la industria de la minería a las comunidades indígenas incluyen:

La limitada regulación ambiental y la continuada violación de los derechos de los amerindios, las concesiones mineras entregadas a terceros de parte de la comisión de geología y minas de Guyana (Guyana Geology and Mines Commission, GGMC) sobre las tierras tradicionales de los amerindios sin el conocimiento o sin un consentimiento libre, previo e informado (FPIC) de las comu- 
nidades afectadas, según lo requiere el decreto Amerindio (aunque FPIC se aplica únicamente a la minería de pequeña y mediana escala sobre o cerca de las tierras con títulos), la corrupción de los líderes comunitarios por los intereses mineros, el apoyo caso por caso para el entrenamiento en la minería de bajo impacto, la administración débil o que no rinde cuentas por los aparatos de dragado en las comunidades, sin que haya todavía estándares acordados en los ámbitos locales o nacionales para la minería de bajo impacto en la comunidad [y] estándares mineros de bajo impacto como los desarrollados por la Association for Responsible Mining (ARM) requiere revisiones para ajustarse a las actuales prácticas de la minería en Guyana (Griffiths y Anselmo, 2010).

El convenio de preservación de los productos maderables que el gobierno de Guyana firmó con el gobierno de Noruega para recibir hasta 250 millones de dólares, durante un periodo de cinco años, ha derivado en medidas regulatorias a las que se oponen los pequeños mineros. El gobierno impuso un periodo de espera de seis meses para la aprobación de permisos de minería, y así estimular la recolección controlada en los bosques de parte de los aserradores antes de que se permita a los mineros de oro comenzar a excavar en las mismas áreas. La moratoria se proponía abordar también el problema de la minería clandestina. Igualmente, el gobierno dejó de conceder permisos de minería en New River «hasta nuevo aviso» a la luz de las amplias preocupaciones de parte de las comunidades indígenas en el área (Demerara Waves, 5 de julio, 2012).

Este congelamiento produjo una situación de conflicto pues los mineros, airados, acusaron al gobierno de abusar de sus poderes. Los mineros creen que el gobierno lo que quiere es evitar que ellos talen los árboles que tienen valor comercial para la industria de la madera. Acudieron a su organización, la Guyana Gold and Diamond Association (GGDMA), que organizó una asamblea de emergencia donde se aprobó una moción de no confianza hacia el ministerio de gobierno responsable de la minería y recolectó dinero para enfrentar la 
moratoria en las cortes. La GGDMA amenazó con protestas en las calles si no se lograba un compromiso y el gobierno anunció que la prohibición sería de tan sólo un mes. Los mineros argumentaron que estaban conscientes de los problemas ambientales y de otras índoles de la industria de la minería, que los mineros que fueran atrapados violando las leyes del país y destruyendo el ambiente debían de ser procesados, pero que toda la industria no tenía que sufrir las violaciones de los mineros errantes (Caribbean360, 23 de julio, 2012).

El conflicto ha llevado a la renuncia del presidente de GGDMA, quien fue expulsado por los mineros argumentando que estaba alineándose con el gobierno en la disputa. Aproximadamente, cuatro mil mineros recurrieron a cerrar los accesos al pueblo minero de Bartica en protesta contra la medida. Se calcula que Guyana tiene 25 mil mineros, cerca de una tercera parte provenientes de Brasil (Wilkinson, 2010). Sin duda, el gobierno de Guyana ha ejercitado una preferencia para complacer al Banco Mundial y Noruega respecto a los mineros en pequeña y mediana escala, que son los primeros en sentir el apretón de los controles más estrechos y las nuevas reglas más rigurosas en la industria de la minería del oro y el diamante.

Las mujeres están participando cada vez más en el sector extractivo de recursos naturales en Guyana, como mineras, cocineras, trabajadoras sexuales. El tráfico de personas - que incluye a mujeres y niñas en la prostitución forzada en la industria del oro para generar ganancias para los traficantes y el placer de los mineros - es un importante tema de preocupación. El informe sobre tráfico de personas del Departamento de Estado de Estados Unidos para 2012 afirmaba: «El limitado control del gobierno de Guyana de amplias regiones interiores, combinado con las ganancias de la minería de oro y la prostitución que acompaña a la industria, ofrece condiciones conducentes al tráfico» (us State Department, 2012). El reporte establecía que «los guyaneses provenientes de áreas rurales, económicamente deprimidas son especialmente vulnerables al tráfico en las áreas mineras y en los centros urbanos». Las prácticas de uso de mano de obra infantil en la industria de la minería y en el sector de los productos maderables ayudan a acrecentar los bolsillos de los 
mineros y de las compañías de productos maderables. La GGDMA no cuenta con estadísticas de los menores que trabajan en el sector minero, pero algunas estimaciones burdas ubican las cifras en cientos.

Los problemas que enfrentan las mujeres mineras las han obligado a formar la Guyana Women's Miners Association (Gwma). Más de 70 mujeres se han unido a la GWMA, un indicio del número creciente de mujeres en busca de oro y diamantes. Las mujeres mineras tienen sus propios dragados, mientras que otras trabajan como cocineras. Estas mujeres argumentan que trabajar en las minas es aún más problemático para ellas que para los hombres. El aspecto físico de la minería es un importante desafío en sí mismo para las mujeres que deben lidiar con el abuso diario, la explotación, la discriminación, las agresiones y la estigmatización como prostitutas (Stabroek News, 2012).

\section{Conclusión}

El sector de la extracción se ubica indudablemente a la cabeza de la economía de Guyana en términos de ganancias por exportaciones. La producción declarada de oro se ha incrementado consistentemente desde 2006, aun en ausencia de minas a gran escala de propiedad extranjera. La producción declarada de oro en pequeña escala se ha incrementado entre 2003 y 2011, mientras que los diamantes nunca lograron su nivel de 2004. En 2011 la producción de bauxita estaba por debajo del nivel logrado en 2001. El capital proveniente de las economías emergentes se dirige exclusivamente a la producción de bauxita, mientras que el capital proveniente de otros países participa primordialmente en la exploración. Los incentivos a la inversión y el régimen fiscal están hechos para seducir a las compañías mineras extranjeras. El sector privado local y extranjero recibieron la mayor parte de la inversión extranjera directa, la mayor parte de la cual iba dirigida al transporte y telecomunicaciones, seguida de la minería, entre 2007 y 2010. La industria de la bauxita ha visto el más violento conflicto y las tácticas de clase en contra de los sindicatos con el capital extrac- 
tivo. La alteración de las formas de sustento de los pueblos indígenas, la destrucción del ambiente - la mayor parte del cual está asociado ahora con los pequeños mineros en ausencia de alguna mina de gran escala-, la decadencia social en las comunidades mineras que se evidencia por el incremento en el delito, la prostitución, el tráfico de personas, la resistencia de los pequeños mineros en contra de la regulación del gobierno y las preocupaciones de las mujeres mineras son características críticas de la operación del capital extractivo en Guyana.

$\mathrm{Ni}$ el enfoque del Estado autoritario poscolonial ni la correspondiente al nuevo Estado autoritario a la extracción de recursos naturales ha traído a Guyana el desarrollo económico sostenido. Aunque las industrias extractivas siguen siendo centrales para la economía de Guyana, no han logrado desarrollar al país. Su impacto social no ha transformado las condiciones de pobreza en las comunidades mineras ni en el país en su totalidad. Según el informe de progreso de las Metas de Desarrollo del Milenio para Guyana en 2011, aproximadamente $19 \%$ de la población vivía en pobreza extrema en 2006 y nacionalmente $36.1 \%$ de la gente vivía en pobreza el mismo año. En las áreas mineras de oro como Cuyuni-Mazaruni, 61.4\% de la población vivía en pobreza en 2006; en Potaro-Siparuni el porcentaje era de 94.3\%; en la parte alta de Takatu y en la parte alta de Essequibo era 74.4\% (Gobierno de Guyana, 2011). Los pueblos indígenas son los principales habitantes de estas áreas mineras, que están ubicadas en el interior de Guyana.

Fue la agitación sindical la que forzó a las compañías de bauxita a introducir prestaciones no salariales para los trabajadores y las comunidades en la industria (Canterbury, 2003). Estas prestaciones comenzaron a erosionarse después de que fueron nacionalizadas las compañías y el ajuste estructural dio el último golpe a su destrucción por medio de la mercantilización. El capital extractivo en la industria de la actualidad no tiene que preocuparse por proporcionar a comunidad alguna y a muchos trabajadores las prestaciones: el ajuste estructural ha retirado de ellos los costos de la fuerza de trabajo de las compañías. 
A la luz de la aparente maldición de los recursos, el asunto es si Guyana debería quedarse con los recursos naturales como la base de su estructura económica o buscar desmantelarla y diversificarla. La extracción de recursos en Guyana sigue estando al nivel de la producción primaria con nulo o poco valor añadido. La diversificación y sustentabilidad de la economía basada en los recursos naturales requiere un valor agregado muy significativo en la producción primaria. La dependencia del capital extractivo extranjero en la extracción de recursos naturales pone en condiciones al país para ser objeto de dominio exterior. La intensidad de capital del capital extractivo en las industrias extractivas tiene un impacto negativo en la generación de empleos. Una economía basada en los recursos naturales está sujeta a las variaciones de los precios mundiales de las mercancías para ser viable y el costo para el ambiente es muy alto en los países como Guyana, donde los recursos están ubicados en la selva tropical prístina (Thomas, 2012).

Es necesario un nuevo modelo de extracción de recursos que restaure las prestaciones no salariales a los trabajadores y sus comunidades. Sería éste un buen punto de partida para mejorar las condiciones de vida en los debilitados pueblos mineros. El Estado debería evitar generalizar a todo el país las prestaciones que ofrecen las compañías mineras en sus comunidades, que se hacen posibles por medio del trabajo de los mineros. Además, al tomar más de las compañías mineras en forma de tarifas e impuestos, el gobierno dispondría de más recursos para ampliar el gasto social a nivel nacional. Finalmente, el gobierno debería insistir en controlar los recursos naturales y buscar maneras alternativas de extraer y comerciar dentro de los acuerdos, como la Alternativa Bolivariana para América Latina y el Petrocaribe.

\section{REFERENCIAS}

Bulkan, Janette (2011), «Red Star over Guyana”: Colonial-style Grabbing of Natural Resources but New Grabbers», trabajo presentado en el 
Congreso Internacional sobre Global Land Grabbing, Institute of Development Studies, University of Sussex, 6-8 de abril.

Canterbury, Dennis (2003), «Community Development Through Community Non-Wage Benefits in Guyana's Mineral Sector», Canadian Journal of Development Studies, volumen 24, número 3, pp. 303-318.

(2005), Neoliberal democratization and New Authoritarianism, Aldershot and Burlington, Ashgate Publishers, 2005.

Caribbean 360 (2013), «Us seizes gold bars from Curacao, site of multimillion dollar heist», 12 de enero.

(2012), «Guyana gold wealth fleeing across the border», 23 de julio.

Chabrol, Denis (2013), «Guyana dismissed us' concern over enforcement of money laundering, other laws», Demerara Waves, 14 de marzo.

(2013), «Police responsible for Linden "shooting" to scare "hostile" crowd justified», Demerara Waves, 1 de marzo.

Demerara Waves (2012), «Guyana halts granting new river mining permits in the wake of massive environmental degradation», 5 de julio.

Edmonds, Kevin (2013), «Everything That Glitters Isn't Green in Guyana», North American Congress on Latin America, 13 de julio.

Edwards, Walter y Kean Gibson (1979), «An Ethnohistory of Amerindians of Guyana», Ethnohistory, volumen 26, número 3, pp. 161-175.

Farmland.org (2008), «Guyana seeking agro-investors in the US», 28 de noviembre. (2009), «Guyana yet to see huge regional investment in agri sector», 22 de junio.

First Bauxite Corporation (2012), First Bauxite Corporation Announces Appointment of New Director and Option Grant, 17 de agosto.

Gobierno de Guyana (2003), Review of Guyana's Foreign Trade, 2001 y 2002, Ministry of Foreign Trade and International Cooperation, Georgetown, Guyana.

(2006), Enhancing National Competitiveness: A National Competiveness Strategy for Guyana (Draft Policy Paper II), Gobierno de Guyana en sociedad con el sector privado, mayo. 
(2011), Millennium Development Goals: Guyana Progress Report 2011, Ministry of Finance, Georgetown, Guyana.

(2012), Budget 2012: Remaining on Course, United in Purpose, Prosperity for All, Ministry of Finance, Georgetown, 30 de marzo.

GRAIN (2010), Land Grabbing in Latin America, Georgetown, 29 de marzo.

Griffiths, Tom y Lawrence Anselmo (2010), Indigenous Peoples and Sustainable Livelihoods in Guyana: An Overview of Experiences and Potential Opportunities, Amerindian People's Association, Forest People Program, The North-South Institute, Georgetown, Reino Unido, Ottawa.

Guyana Rice Development Board (2012), Annual Report 2011, Georgetown, en 〈http://www.cqbosai.com/en/m_aboutus/content.asp?id=16\&pid=17〉.

Kaieteur News (2012), «Indian Coffee Company Ships Out 50 Containers of Logs in 2 Months», Kaieteur News Online, 5 de abril.

The Tripoli Post (2009), «Libya to Boost Agriculture Ties with Guyana», 7 de marzo.

Marketwire (20 de marzo de 2012), «ReE International Acquires Rare Earth Property With Estimated Value of \$10 Million».

(2012), «Argus Receives Title and Uranium License for the Large-scale, Drill-ready Kaituma Uranium/Gold Project», 31 de enero.

Mars, Perry (1998), «Socio-Political Impact of Large Scale Gold Mining in Guyana: Resolving Tensions Between Capital and Labor», en Dennis C. Canterbury (editor), Guyana's Gold Industry: Evolution, Structure, Impacts and Non-Wage Benefits, Transition, número especial 27-28, Institute of Development Studies, University of Guyana, pp. 57-70

Merrill, Tim (editor) (1992), Guyana: A Country Study, Washington, gro for the Library of Congress.

Ministry of Natural Resources and the Environment (2012), Mining Opportunities in Guyana, Quarterly Mining Supplement, marzo, Georgetown. RAM, Christopher (2012), «The economics of Linden and electricity rates: Region Ten is not a burden on, but a contributor to the state», Sunday Stabroek Feature, 29 de julio. 
Rawana, Dev (1998), «Report-Survey on Environmental and Health Impacts», en Dennis C. Canterbury (editor), Guyana's Gold Industry: Evolution, Structure, Impacts and Non-Wage Benefits, Transition, número especial 27-28, Institute of Development Studies, University of Guyana. Report of Commission of Inquiry Into Discharge of Cyanide and Other Noxious Substances Into the Omai and Essequibo Rivers (1996), Georgetown, 5 de enero.

Reuters (2009), «Strike stops output at Rasul bauxite mine in Guyana», 24 de noviembre.

Stabroek News (2012), Women Miners, Georgetown, 16 de febrero.

The Gleaner (2012), «Illegal Foreign Miners Held In Sweep By Guyanese Law Enforcement», 25 de abril.

Thomas, Clive (1983), «State Capitalism in Guyana: An Assessment of Burnham's Cooperative Socialist Republic», en Fitzroy Ambursley y Robin Cohen (editores), Crisis in the Caribbean, Monthly Review, Nueva York. (1998), «Omai's Gold Production in Guyana», en Dennis C. Canterbury (editores), Guyana's Gold Industry: Evolution, Structure, Impacts and Non-Wage Benefits, Transition, número especial 27-28, Institute of Development Studies, University of Guyana, pp. 37-56 (2012), Guyana: Economic Performance and Outlook (The Recent Scramble for Natural Resources), Institute of Development Studies, University of Guyana, abril.

(2012), The LCDs Guyana-Norway Agreement and Environmental Issues Related to Global Warming and Climate Change, Sunday Stabroek, News Columns, November 29, 2009-August 1, 2010, Institute of Development Studies, University of Guyana.

Trevin, Jorge y Robert Nasi (2009), Forest Law Enforcement and Governance and Forest Practices in Guyana, Center for International Forestry Research (CIFOR), Bogor.

us Bureau of International Narcotics and Law Enforcement Affairs (2013), International Narcotics Control Strategy Report, 5 de marzo. 
us Department of State (2012), Investment Climate Statement-Guyana, Bureau of Economic and Business Affairs, Washington DC, junio.

us State Department (2012), Trafficking in Persons Report 2012, Washington, DC, junio.

Wilkinson, Bert (2010), «Guyana: Pro-Forest Measures Anger Miners», IPS, 12 de febrero. (2012), «Runaway Gold Prices Spark Major Headaches for Guyana», IPS, 29 de mayo. 
